\title{
Üriner sistem enfeksiyonlarından izole edilen Escherichia coli ve Klebsiella pneumoniae suşlarında florokinolon direncini etkileyen risk faktörlerinin değerlendirilmesi
}

\author{
Evaluation of risk factors associated with fluoroquinolone-resistant Escherichia \\ coli and Klebsiella pneumoniae urinary tract infections \\ Pınar Şen ${ }^{1}$ Bora İrer ${ }^{2}$ BD $\quad$ Tuna Demirdal $^{3}$ Yusuf Engin Yaygın ${ }^{4}$ (D) \\ ${ }^{1}$ Saruhanlı Devlet Hastanesi, Enfeksiyon Hastalıkları ve Klinik Mikrobiyoloji Kliniği, Manisa, Türkiye \\ ${ }^{2}$ İzmir Büyükşehir Belediyesi Eşrefpaşa Hastanesi, Üroloji Kliniği, İzmir, Türkiye \\ ${ }^{3}$ İzmir Katip Çelebi Üniversitesi, Atatürk Eğitim ve Araştırma Hastanesi, Enfeksiyon Hastalıkları ve \\ Klinik Mikrobiyoloji Kliniği, İzmir, Türkiye \\ ${ }^{4}$ İzmir Büyükşehir Belediyesi Eşrefpaşa Hastanesi, Tıbbi Mikrobiyoloji Kliniği, İzmir, Türkiye
}

\section{Öz}

Amaç: Antimikrobiyal direnç oranlarındaki artış, üriner sistem enfeksiyonlarında oral ampirik tedavi seçeneklerini kısıtlamaktadır. Dirençle ilgili risk faktörlerini belirlemek, ampirik antibiyotik seçimine yol göstermesi açısından önemlidir. Çalışmamızda, polikliniğe ayaktan başvuran hastaların idrar kültürlerinden izole edilen Escherichia coli (E. coli) ve Klebsiella pneumoniae (K. pneumoniae) suşlarında florokinolon direnci ve risk faktörlerini değerlendirmeyi amaçladık.

Gereç ve Yöntem: Ocak 2015-Aralık 2017 tarihleri arasında üroloji polikliniğine başvuran ve idrar kültüründe $\mathrm{E}$. coli ve K. pneumoniae üremesi olan 76 hastanın demografik verileri geriye dönük olarak değerlendirildi. Florokinolon direncine etki edebilecek olası risk faktörleri istatistiksel olarak incelendi.

Bulgular: Hastaların 60 (\%78.9)' । kadın ve 16 (\% 21.1)' i erkekti ve yaş ortalaması $54.1 \pm 19.6$ yıl olarak bulundu. Florokinolon direnci \%55.3, genişlemiş spektrumlu beta-laktamaz pozitifliği \%15.8 olarak saptandı. Florokinolon direnci açısından komplike idrar yolu enfeksiyonu $(p=0.009)$, üriner sistem taşı $(p$ $=0.014)$, üropatoloji $(p=0.002)$, ürolojik girişim öyküsü $(p=0.040)$ ve önceden antibiyotik kullanım öyküsü $(p<0.001)$ anlamlı bulundu. Üriner sistem taşı, üropatoloji, ürolojik girişim öyküsü ve komplike idrar yolu enfeksiyonu varlığı ile florokinolon direnci arasında zayıf derecede pozitif yönde; önceden antibiyotik kullanım öyküsü ile florokinolon direnci arasında ise orta derecede pozitif yönde ve istatistiksel olarak anlamlı korelasyon bulundu $(p<0.05)$. Son 6 ay içinde antibiyotik kullanımı öyküsü, florokinolon direnci açısından bağımsız risk faktörü olarak bulundu ( $p=0.005)$.

Sonuç: Antibiyotik direncine neden olan önlenebilir faktörlerin belirlenerek gerekli önlemlerin alınması, hem ampirik antibiyoterapi seçiminde yol gösterici olması hem de akılcı antibiyotik kullanımı ile birlikte direnç oranlarını azaltabilmek açısından önemlidir.

Anahtar Sözcükler: Direnç, florokinolon, risk faktörleri, üriner sistem enfeksiyonu.

\footnotetext{
Abstract

Yazışma Adresi: Pınar Sen

Saruhanlı Devlet Hastanesi, Enfeksiyon Hastalıkları ve Klinik

Mikrobiyoloji Kliniği, Manisa, Türkiye

E-mail: pinarozdemirsen@gmail.com

Makalenin Geliş Tarihi:15.05.2018 Kabul Tarihi: 05.07.2018
}

Aim: The increased antimicrobial resistance rates limit oral empirical treatment options in urinary tract infections. Determining risk factors associated with antibiotic resistance is important in terms of empirical antibiotic selection. We aimed to evaluate fluoroquinolone resistance and risk factors in Escherichia coli (E. coli) and Klebsiella pneumoniae (K. pneumoniae) strains isolated from urine cultures. 
Materials and Methods: A total of 76 patients who were admitted to the outpatient urology clinic were analyzed retrospectively from January 2015 through December 2017. Possible risk factors associated with fluoroquinolone resistance were analyzed statistically.

Results: Sixty (78.9\%) of the patients were female and 16 (21.1\%) were male and mean age was $54.1 \pm$ 19.6 years. The fluoroquinolone resistance was $55.3 \%$ and extended spectrum beta-lactamase positivity rates were $15.8 \%$. Complicated urinary tract infection $(p=0.009)$, urolithiasis $(p=0.014)$, uropathology $(p=0.002)$, urological intervention $(p=0.040)$ and prior antibiotic use $(p<0.001)$ were significantly associated with fluoroquinolone resistance. The weak positive correlation was found between complicated urinary tract infection, urolithiasis, uropathology, urological intervention and fluoroquinolone resistance and prior antibiotic use was showed moderately positive correlation with fluoroquinolone resistance $(p<0.05)$. Prior antibiotic use is identified as an independent risk factor for fluoroquinolone resistance $(p=0.005)$.

Conclusion: Identification of preventable factors leading to antibiotic resistance and taking the necessary precautions are important both in empirical antibiotherapy selection and in decreasing resistance rates together with rational antibiotic use.

Keywords: Fluoroquinolone, resistance, risk factors, urinary tract infection.

\section{Giriş}

Üriner sistem enfeksiyonları, tüm yaş gruplarında ayaktan ve yatan hastalarda en sık rastlanan enfeksiyonların başında gelmektedir (1). Dünya genelinde her yıl yaklaşık 150 milyon kişinin üriner sistem enfeksiyonu tanısı aldığı tahmin edilmektedir (2). Asemptomatik bakteriüri ve sistit gibi hafif klinik tablolardan piyelonefrit ve ürosepsise kadar değişebilen geniş klinik yelpazesi bulunan bu enfeksiyonlar önemli morbidite ve mortalite nedenidir (1,3). Enterobacteriaceae üyelerinden Escherichia coli (E. coli) ve Klebsiella pneumoniae (K. pneumoniae) üriner sistem enfeksiyonlarında en sık izole edilen etkenlerdendir. $\mathrm{Bu}$ bakteriler toplum ve hastane kaynaklı üriner sistem enfeksiyonlarının yaklaşık $\% 80$ 'inden sorumludur (3).

Uygunsuz antibiyotik kullanımı ve hasta uyumsuzluğu nedeniyle sı kullanılan antibiyotiklere karşı hızla direnç gelişmektedir $(3,4)$. Infectious Diseases Society of America (IDSA) tarafından yayımlanan rehberde komplike olmayan sistitin en sık antibiyotik kullanım endikasyonları arasında yer aldığı bildirilmiştir (5). Antimikrobiyal direnç oranlarındaki artış, üriner sistem enfeksiyonlarında oral ampirik tedavi seçeneklerini kısıtlamaktadır (6). Antimikrobiyal direnç oranlarındaki artışa rağmen, florokinolonlar üriner sistem enfeksiyonlarının tedavisinde en sık kullanılan antibiyotik grubu olmaya devam etmektedir (7). Antibiyotik direncine neden olan risk faktörlerinin belirlenmesi, uygun ampirik antibiyotik seçimine yardımcı olmak için ek bilgi sağlayabilir.
Ayrıca, özellikle antimikrobiyal dirence neden olan değiştirilebilir faktörlerin belirlenerek gerekli önlemlerin alınması direnç oranlarını düşürmede önemlidir. Bu çalışmada, polikliniğe ayaktan başvuran hastaların idrar kültürlerinden izole edilen $E$. coli ve $K$. pneumoniae suşlarında florokinolon direnci ve risk faktörlerinin değerlendirilmesi amaçlanmıştır.

\section{Gereç ve Yöntem}

\section{Demografik veriler}

Ocak 2015 - Aralık 2017 tarihleri arasında üroloji polikliniğine ayaktan başvuran ve idrar yolu enfeksiyonu ön tanısıyla istenen idrar kültüründe $E$. coli ve $K$. pneumoniae üremesi olan 76 hasta geriye dönük olarak değerlendirildi. Florokinolon direncine yol açması olası risk faktörlerinden üriner sistem taşı varlığı, üropatolojik durumlar (benign prostat hiperplazisi, nörojenik mesane ve ürolojik maligniteler), ürolojik girişim öyküsü (açık ya da endoskopik cerrahi girişim, prostat biyopsisi, sonda takılması), diyabet öyküsü, son 6 ay içinde hastanede yatış varlığı ve son 6 ay içinde en az 48 saat boyunca antibiyotik kullanım öyküsü değerlendirildi.

\section{Mikrobiyolojik inceleme}

Steril şartlarda alınan orta akım idrar örnekleri 0.01 $\mu$ L'lik standart öze kullanılarak \%5 koyun kanlı agar ve Eosin-Methylene Blue (EMB) (RTA, Türkiye) agar besiyerlerinin yüzeyine kantitatif olarak ekildi. Besi yeri plakları etüvde $35-37^{\circ} \mathrm{C}$ 'de 18-24 saat aerobik ortamda inkübe edildi. Koyun 
kanlı agardaki koloni sayısı $\geq 10^{5}$ CFU (colonyforming units-koloni oluşturan birim) $/ \mathrm{ml}$ olan ve yüzeyinde tek tip bakteri üremesi olan besi yeri plakları incelemeye alındı. İdrar kültüründe $10^{5}$ CFU/ml'den az üreme olan ya da birden fazla türde üreme saptanan hastalar çalışma dışı bırakıldı.

Elde edilen suşlar konvansiyonel yöntemler kullanılarak tanımlandı. Üreyen bakteriler TSI, üre, sitrat, indol (RTA, Türkiye) besi yerine pasajlanarak indol üretimi, üre hidrolizi, hareket, laktoz ve diğer şekerlerin fermentasyonu, sitrat metabolizması varlığına göre tanımlandı. $\mathrm{Bu}$ yöntemlerle tanımlanamayan suşların tanımlaması BD Crystal Gram Negative Identification (Becton Dickinson, ABD) kiti ile yapıldı.

Aerobik kültür sonucu üreyen kolonilerden suş tanımlama ve antibiyogram profili agar disk difüzyon yöntemi kullanılarak belirlendi. Disk difüzyon yöntemi Mueller-Hinton (RTA, Türkiye) agar besi yeri kullanılarak yapıldı. Mueller-Hinton agar besi yerine 0.5 McFarland bulanıklıkta hazırlanan bakteri süspansiyonu eküvyonla inoküle edilerek antibiyotik duyarlılıkları European Committee on Antimicrobial Susceptibility Testing (EUCAST) (EUCAST breakpoint Table v.7.1) (8) önerileri doğrultusunda gerçekleştirildi.

İdrar kültürlerinde üreyen suşlarda GSBL varlığı için çift disk sinerji testi kullanıldı (9). Mueller Hinton Agar besi yeri üzerine merkezde amoksisilin-klavulanik asit (AMC, 20/10 $\mu \mathrm{g}$ ) olmak üzere çevresine disk merkezleri arası uzaklık 25 $\mathrm{mm}$ olacak şekilde seftazidim (CAZ, $10 \mu \mathrm{g}$ ), seftriakson (CRO, $30 \mu \mathrm{g}$ ), sefotaksim (CTX, $5 \mu \mathrm{g}$ ) ve aztreonam (ATM, $30 \mu \mathrm{g}$ ) diskleri yerleştirildi. Plakların $\quad 35-37^{\circ} \mathrm{C}$ 'de $\quad 18-24$ saatlik inkübasyonundan sonra CAZ, CRO, CTX ve ATM diskleri çevresindeki inhibisyon zonunun AMC diskine doğru $\geq 5 \mathrm{~cm}$ genişlemesi ve/veya iki inhibisyon zonu arasında bakteri üreyen alanlarda üreme olmayan bir bölgenin varlığı ile GSBL üretiminin olduğuna karar verildi.

Kalite kontrol için E.coli ATCC 25922 ve E.coli ATCC 35218 standart suşları kullanıldı.

\section{Ístatistiksel Analiz}

Çalışmada elde edilen verilerin değerlendirilmesinde Statistical Package for Social Sciences (SPSS) Version 22,0 (Chicago, IL) paket programı kullanıldı. Sürekli değişkenler için t-test, kategorik değişkenler için ki-kare testi kullanıldı. Florokinolon direnci için potansiyel risk faktörlerinin belirlenmesinde çoklu regresyon analizi, florokinolon direnci ile risk faktörleri arasındaki ilişkinin belirlenmesi için Pearson korelasyon testi kullanıldı. P değeri $0,05^{\prime}$ in altında olduğunda istatistiksel olarak anlamlı kabul edildi.

\section{Bulgular}

Hastaların 60'ı (\%78,9) kadın ve 16'sı (\%21,1) erkekti ve yaş ortalaması $54,1 \pm 19,6$ yıl olarak bulundu. Yaş grupları dağılımı incelendiğinde, 40 yaş altında 20 (\%26,3), 40-60 yaş arasında 23 $(\% 30,3)$ ve 60 yaş üstünde $33(\% 43,4)$ hasta bulunmaktaydı. Risk faktörleri değerlendirildiğinde; hastaların 52'sinde $(\% 31,6)$ komplike idrar yolu enfeksiyonu, 27'sinde $(\% 35,5)$ üriner sistem taşı, 44 'ünde $(\% 57,9)$ üropatolojik durumlar, $25^{\prime}$ inde $(\% 32,9)$ ürolojik girişim öyküsü, 21'inde $(\% 27,6)$ diyabet hastalığı, 32'sinde $(\% 42,1)$ son 6 ay içinde hastanede yatış öyküsü ve 61 'inde $(\% 80,3)$ son 6 ay içinde antibiyotik kullanım öyküsü bulunmaktaydı. Florokinolon direnci \%55,3 (42/76), genişlemiş spektrumlu beta-laktamaz (GSBL) pozitifliği \%15,8 (12/76), nitrofurantoin direnci $\% 17,9(12 / 67)$ ve amikasin direnci \%3,9 (3/76) olarak saptandı.

Florokinolon direnci bulunan hastalar ile duyarlı bulunan hastalar arasında risk faktörleri karşılaştırıldığında komplike idrar yolu enfeksiyonu $(p=0,009)$, üriner sistem taşı $(p=0,014)$, üropatoloji $(p=0,002)$, ürolojik girişim öyküsü $(p=0,040)$ ve önceden antibiyotik kullanım öyküsü $(p<0,001)$ varlığı açısından anlamlı farklııık bulundu (Tablo1). Cinsiyet, diyabet hastalığı ve son 6 ay içinde hastaneye yatış öyküsü açısından florokinolon dirençli ve duyarlı hasta grupları arasında anlamlı farklılık yoktu (sırasıyla $p=0,512, \quad p=0,839$, $\mathrm{p}=0,279)$ (Tablo-2).

Üriner sistem taşı $(r=0,231, p=0,014)$, üropatoloji $(r=0,358, \quad p=0,001)$, ürolojik girişim öyküsü $(r=0,236, \quad p=0,040)$ ve komplike idrar yolu enfeksiyonu varlığı $(r=0,300, \quad p=0,009)$ ile florokinolon direnci arasında zayıf derecede pozitif yönde; son 6 ay içinde antibiyotik kullanım öyküsü $(r=0,418, p<0,001)$ ile florokinolon direnci arasında ise orta derecede pozitif yönde ve istatistiksel olarak anlamlı korelasyon bulundu (Tablo-2). Çok değişkenli lojistik regresyon analizinde, belirtilen risk faktörleri arasından sadece son 6 ay içinde antibiyotik kullanımı öyküsü, florokinolon direnci açısından bağımsız risk faktörü olarak bulundu $(p=0,005)($ Tablo-3). 
Tablo-1. Florokinolon Dirençli ve Duyarlı Grupların Karşılaştırılması.

\begin{tabular}{|c|c|c|c|}
\hline & Dirençli (n,\%) & Duyarlı (n, \%) & $\mathbf{p}$ \\
\hline $\begin{array}{l}\text { Yaş (ortalama } \pm \text { standart sapma) } \\
\text { Yaş grubu }\end{array}$ & $55,1 \pm 19,9$ & $52,8 \pm 19,6$ & 0,627 \\
\hline$<40$ yaş & $10(\% 23,8)$ & $10(\% 29,4)$ & \multirow{3}{*}{0,856} \\
\hline $40-60$ yaş & $13(\% 31)$ & $10(\% 29,4)$ & \\
\hline $\begin{array}{l}\geq 60 \text { yaş } \\
\text { Cinsiyet }\end{array}$ & $19(\% 45,2)$ & $14(\% 41,2)$ & \\
\hline Kadın & $32(\% 76,2)$ & $28(\% 82,4)$ & \multirow[t]{3}{*}{0,512} \\
\hline Erkek & $10(\% 23,8)$ & $6(\% 17,6)$ & \\
\hline Komplike üriner sistem enfeksiyc & & & \\
\hline Komplike & $34(\% 81)$ & $18(\% 52,9)$ & \multirow[t]{2}{*}{0,009} \\
\hline Değil & $8(\% 19)$ & $16(\% 47,1)$ & \\
\hline Üriner sistem taşı & & & \\
\hline Yok & $22(\% 52,4)$ & $27(\% 79,4)$ & \multirow[t]{2}{*}{0,014} \\
\hline Var & $20(\% 47,6)$ & $7(\% 20,6)$ & \\
\hline Üropatoloji & & & \multirow{3}{*}{0,002} \\
\hline Yok & $11(\% 26,2)$ & $21(\% 61,8)$ & \\
\hline Var & $31(\% 73,8)$ & $13(\% 38,2)$ & \\
\hline Ürolojik Girişim & & & \\
\hline Yok & $24(\% 57,1)$ & $27(\% 79,4)$ & \multirow[t]{2}{*}{0,040} \\
\hline Var & $18(\% 42,9)$ & $7(\% 20,6)$ & \\
\hline Diabetes Mellitus & & & \\
\hline Yok & $30(\% 71,4)$ & $25(\% 73,5)$ & \multirow[t]{2}{*}{0,839} \\
\hline Var & $12(\% 28,6)$ & $9(\% 26,5)$ & \\
\hline Hastanede yatış öyküsü & & & \multirow{3}{*}{0,279} \\
\hline Yok & $22(\% 52,4)$ & $22(\% 64,7)$ & \\
\hline Var & $20(\% 47,6)$ & $12(\% 35,3)$ & \\
\hline Önceden antibiyotik kullanımı & & & \\
\hline Yok & $2(\% 4,8)$ & $13(\% 38,2)$ & \multirow[t]{2}{*}{$<0,001$} \\
\hline Var & $40(\% 95,2)$ & $21(\% 61,8)$ & \\
\hline ESBL pozitifliği & & & \\
\hline Yok & $32(\% 76,2)$ & $32(\% 94,1)$ & \multirow[t]{2}{*}{0,033} \\
\hline Var & $10(\% 23,8)$ & $2(\% 5,9)$ & \\
\hline
\end{tabular}

Tablo-2. Florokinolon Direnci ile Risk Faktörlerinin İlişkisi

\begin{tabular}{lcc}
\hline Risk faktörleri & r değeri & p değeri \\
\hline Komplike üriner sistem enfeksiyonu & 0,300 & 0,009 \\
Üriner sistem taşı & 0,231 & 0,014 \\
Üropatoloji & 0,358 & 0,001 \\
Ürolojik girişim & 0,236 & 0,040 \\
Önceden antibiyotik kullanımı & 0,418 & $<0,001$ \\
\hline
\end{tabular}

Tablo-3. Florokinolon Direnci İçin Risk Faktörlerinin Çok Değişkenli Lojistik Regresyon Analizi.

\begin{tabular}{lcccc}
\hline Risk Faktörleri & B & Odds oranı & \%95 Güven aralığı & p \\
\hline Komplike üriner sistem enfeksiyonu & $-0,042$ & 0,959 & $0,160-5,763$ & 0,963 \\
Üriner sistem taşı & $-0,741$ & 0,477 & $0,110-2,058$ & 0,321 \\
Üropatoloji & $-0,951$ & 0,387 & $0,045-3,301$ & 0,385 \\
Ürolojik girişim & 0,152 & 1,164 & $0,259-5,240$ & 0,843 \\
Önceden antibiyotik kullanımı & $-2,473$ & 0,084 & $0,015-0,466$ & 0,005 \\
\hline
\end{tabular}

B: regresyon katsayısı 


\section{Tartışma}

Florokinolonlar hem toplum hem hastane kökenli enfeksiyonların tedavisinde en sık kullanılan antibiyotiklerdendir (10). Bu grup antibiyotikler yüksek hücre içi ve doku geçişi, Gram-pozitif ve Gram-negatif bakterileri kapsayan geniş antibakteriyel etkinliği, oral biyoyararlanım oranının yüksekliği ve görece az yan etkiye sahip olması nedeniyle tercih sebebi olmaktadır (11). Bu nedenle dünya genelinde reçetelenen antimikrobiyaller arasında dördüncü sırada olup, 2000-2010 yılları arasında reçetelenme oranının \%64 arttığı bildirilmektedir (11).

Antimikrobiyallerin yaygın kullanımı nedeniyle florokinolonlara dirençli ve GSBL üreten üropatojenler dünya genelinde oldukça yaygınlaşmıştır $(9,10)$. Dünya sağlık örgütü $(\mathrm{WHO})$ antimikrobiyal direnç sürveyansında, sık görülen toplum ve hastane kaynaklı enfeksiyonlardan sorumlu uluslararası önemi olan dokuz bakteri tanımlanmıştır (12). Escherichia coli ve $K$. pneumoniae suşları da bu bakteriler arasında yer alan önemli üropatojenlerdendir. WHO tarafından tarif edilen altı bölgenin tümünde (Amerika, Avrupa, Afrika, Doğu Akdeniz, Güney-Doğu Asya ve Batı Pasifik) bu patojenlere karşı yüksek antimikrobiyal direnç oranlarının görüldüğü belirtilmektedir (12). Beş WHO bölgesinden sunulan ulusal verilerde $E$. coli suşlarında kan ve idrar örnekleri dahil olmak üzere florokinolonlara (siprofloksasin, ofloksasin veya norfloksasin) ve üçüncü kuşak sefalosporinlere (seftazidim, sefotaksim veya seftriakson) karşı en az \%50 direnç gelişimi olduğu gösterilmiştir (12). Tüm dünyada siprofloksasine dirençli üropatojen bakteri oranının komplike olmayan üriner sistem enfeksiyonlarında \%2-69, komplike üriner sistem enfeksiyonlarında \%98'den fazla, sağlık bakımı ilişkili üriner sistem enfeksiyonlarında \%6-62 arasında olduğu belirtilmektedir (6). Dalhoff tarafından yapılan çalışmada florokinolon direncinin en yüksek Asya-Pasifik bölgesinde görüldüğü, Kuzey Amerika ve Avrupa'da ise düşükorta düzeyde seyrettiği bildirilmiştir (13). Ülkemizde 2013 yılında yapılan bir meta-analiz çalışmasında bölgelere göre değişmekle birlikte, idrar kültürlerinden izole edilen $E$. coli suşlarında siprofloksasine karşı genel olarak \%24,65 oranında direnç bulunduğu, GSBL üreten $E$. coli suşlarının \%20.98 oranında saptandığı ve bu oranların yıllara göre değerlendirildiğinde artma izlendiği bildirilmiştir (4). Çalışmamızda incelenen üropatojenlerin florokinolon direnci $(\% 55,3)$ ve GSBL oranı $(\% 15,8)$ literatürle benzer olarak yüksek bulundu. Yüksek direnç oranlarımızın, florokinolon ve beta-laktam grubu antibiyotiklerin yaygın olarak kullanılmasına bağlı olduğunu düşünmekteyiz. $\mathrm{Bu}$ nedenle direnç oranlarını düşürebilmek adına florokinolon ve diğer geniş spektrumlu antibiyotik kullanımının hangi endikasyonda olursa olsun seçilmiş hasta grubunda dikkatli kullanılması gerektiği kanaatindeyiz.

Üriner sistem enfeksiyonlarında florokinolon direnci gelişimi açısından yapılan çeşitli çalışmalarda bazı risk faktörleri tanımlanmıştır. İleri yaş, erkek cinsiyet, üriner kateterizasyon, bakımevinde yaşama, komorbidite, önceden florokinolon kullanımı, tekrarlayan üriner sistem enfeksiyonu öyküsü, hastaneye yatış öyküsü ve komplike üriner sistem enfeksiyonu varlığı tanımlanan ortak risk faktörleri arasında yer almaktadır (10-15). Çalışmamızda da benzer olarak florokinolon direnci bulunan hastalar ile direnç bulunmayan hastalar arasında komplike idrar yolu enfeksiyonu ve önceden antibiyotik kullanım öyküsü açısından anlamlı farklılık bulundu. Ancak diğer çalışmaların aksine direnç ile cinsiyet, yaş, komorbidite ve hastaneye yatış öyküsü arasında bir ilişki yoktu. Ek olarak çalışmamızda dirençli ve duyarlı hasta grubu arasında üriner sistem taşı, üriner sistem patolojileri ve ürolojik girişim öyküsü bulunması açısından anlamlı farklııık bulundu. Komplike idrar yolu enfeksiyonu nedenlerinden olan bu üç faktörün antibiyotik direnci gelişimi açısından risk faktörü olarak saptanması, sık tekrarlayan enfeksiyonlara ve önceden antibiyotik kullanımı öyküsüne neden olmaları nedeniyle anlamlı bulunduklarını düşündürmektedir. $\mathrm{Bu}$ bulgudan yola çıkarak, üriner sistem enfeksiyonu nedeniyle ayaktan başvuran hastalarda ampirik antibiyotik tercihi yaparken belirlenen risk faktörlerine ek olarak üriner sistem taşı, üropatoloji ve ürolojik girişim öyküsü gibi komplike edici faktörlerin sorgulanması, bunların varlığında florokinolon dışı seçeneklerin ampirik tedavide seçilmesi daha uygun görünmektedir.

Antimikrobiyallerin etkinliği birçok faktörden etkilenmektedir. Bakteriyel faktörler (duyarlılık, direnç, tolerans, biyofilm ve inokulüm büyüklüğü), 
antimikrobiyal konsantrasyon ve konak faktörleri (serum etkisi ve barsak mikrobiyata etkisi) bunlardan başlıcalarıdır (16). İnsan mikrobiyatası olarak bilinen deri yüzeyinde, orofarenks ve gastrointestinal sistemde bulunan büyük sayı ve çeşitlilikteki mikroorganizma topluluğu, antibiyotik direncinde doğal rezervuar olarak önemli rol oynar (11). Mikrobiyatayı oluşturan tüm mikroorganizmaların kullanım amacından bağımsız olarak tüm antibiyotiklerden etkilenerek antibiyotik direnç genlerinin evrimi ve transferi için önemli bir kaynak oluşturduğu bildirilmiştir (17). Florokinolonlar, oral alım sonrası ince bağırsaktan emilerek büyük kısmı değişmeden idrarla, bir kısmı da safra yoluyla feçesle atılarak elimine edilir. Bu nedenle florokinolonların mikrobiyal ekosistemde yüksek konsantrasyonda bulunduğu gösterilmiştir (18). Sonuç olarak florokinolon kullanımının, mikrobiyatada florokinolon direncini taşıyan mutant suşların seleksiyonuna neden olarak yüksek florokinolon direncine neden olduğu belirtilmiştir (11). Üriner sistem enfeksiyonlarında florokinolon direnci gelişimi açısından yapılan çeşitli çalışmalarda önceden florokinolon kullanımı tanımlanan risk faktörleri arasındadır (10-15). Çalışmamızda farklı olarak ayaktan başvuran hastalarda son 6 ay içinde herhangi bir antibiyotik kullanımının florokinolon direnci açısından bağımsız risk faktörü olduğunu gösterdik. Mikrobiyatanın kullanılan tüm antimikrobiyallerden etkilendiği ve günümüzde antibiyotik direnci gelişiminde en önemli faktörlerden olduğu göz önüne alındığında, risk faktörü olarak sadece önceden florokinolon kullanımının değil, özellikle gastrointestinal sistemde metabolize edilen herhangi bir antibiyotik kullanımı öyküsünün olması daha uygun bir yaklaşım olabilir. Bu konuda yapılacak geniş çaplı ileriye dönük-randomize kontrollü çalışmalarla intiyaç vardır.

Antimikrobiyal direnç gelişimi doğrudan antibiyotik kullanımı ile ilgilidir. Çeşitli nedenlerle kullanılan antibiyotiklerin yaklaşık \%20'sinin gerekli olmadığı tahmin edilmektedir (11). Morgan ve arkadaşları tarafından yapılan bir sistematik derlemede, reçetesiz antibiyotik kullanımının antimikrobiyal direnç gelişiminde önemli bir risk faktörü olduğu belirtilmiştir (19). Bu derlemede antibiyotik erişiminin kısıtlanmadığı toplumlarda antimikrobiyal direncin daha yaygın olduğu, reçetesiz kullanımı önleyen kontrol politikaları geliştirmiş ülkelerde ise antibiyotik kullanımında ve direnç oranlarında düşüş olduğu gösterilmiştir (19). Çalışmamızda incelenen risk faktörleri arasında, önceden antibiyotik kullanımı direnç gelişimi ile ilişkili en önemli faktör olarak bulunmuş olup, antimikrobiyal yönetişim programları ile önlenebilecek bir faktördür. Ülkemizde de 2016 yılı itibari ile uygulanmaya başlanan reçetesiz antibiyotik kullanımının kısıtlanması ve ek akılcı ilaç kullanımı politikalarının yürürlüğe girmesiyle birlikte antimikrobiyal direnç oranlarında düşüşün sağlanacağını öngörebiliriz.

\section{Sonuç}

Sonuç olarak, üriner sistem enfeksiyonlarında ampirik tedavi kararı verirken direnç verilerinin ve direnç için risk faktörlerinin göz önünde bulundurulması gerekmektedir. Özellikle son 6 ay içinde antibiyotik kullanım öyküsü ve komplike üriner sistem enfeksiyonu varlığında ampirik florokinolon kullanımının tedavi başarısızlığına yol açabileceği göz önüne alınmalıdır.

\section{Kaynaklar}

1. Tekin A, Deveci Ö, Dal T, Tekin R, Özekinci T, Dayan S. Üropatojen Escherichia coli izolatlarına fosfomisin ve bazı antibiyotiklerin in vitro etkinliği. Ankem Derg 2012; 26 (2): 61-68.

2. Fasugba O, Gardner A, Mitchell BG, Mnatzaganian G. Ciprofloxacin resistance in community- and hospitalacquired Escherichia coli urinary tract infections: a systematic review and meta-analysis of observational studies. BMC Infect Dis. 2015; 15: 545.

3. Soydan S, Karadağ G, Çalışkan E, Kale E. In vitro susceptibility analysis of Escherichia coli strains isolated from urinary tract infections to fosfomycin, nitrofurantoin and ciprofloxacin. Mediterr J Infect Microb Antimicrob. $2015 ; 4: 3$.

4. Aykan ŞB, Çiftçi İH. Türkiye'de İdrar Kültürlerinden İzole Edilen Escherichia coli Suşlarının Antibiyotiklere Direnç Durumu: Bir Meta-Analiz. Mikrobiyol Bul 2013; 47 (4): 603-618.

5. Gupta K, Hooton TM, Naber KG, et al. Infectious Diseases Society of America; European Society for Microbiology and Infectious Diseases. International clinical practice guideline for the treatment of acute 
uncomplicated cystitis and pyelonephritis in women: a 2010 update by the Infectious Diseases Society of America and the European Society for Microbiology and Infectious Diseases. Clin Infect Dis 2011; 52 (5): e103-120.

6. Dalhoff A. Global fluoroquinolone resistance epidemiology and implications for clinical use. Interdiscip Perspect Infect Dis 2012;2012:976273.

7. Shah A, Justo JA, Bookstaver PB, Kohn J, Albrecht H, Al-Hasan MN. Application of Fluoroquinolone Resistance Score in Management of Complicated Urinary Tract Infections. Antimicrob Agents Chemother. 2017; 61 (5). pii: e02313-16.

8. The European Committee on Antimicrobial Susceptibility Testing. Ref: Breakpoint tables for interpretation of MICs and zone diameters. Version 7.1, 2017. http://www.eucast.org (15/04/2018).

9. Paterson DL, Bonomo RA. Extended-spectrum beta-lactamases: a clinical update. Clin Microbiol Rev 2005;18 (4): 657-686.

10. Kratochwill L, Powers M, McGraw MA, King L, O'Neill JM, Venkat A. Factors associated with ciprofloxacin resistant Escherichia coli urinary tract infections in discharged ED patients. Am J Emerg Med. 2015; 33 (10): 1473-1476.

11. de Lastours V, Fantin B. Impact of fluoroquinolones on human microbiota. Focus on the emergence of antibiotic resistance. Future Microbiol. 2015; 10 (7): 1241-1255.

12. World Health Organisation. Antimicrobial resistance: global report on surveillance. 2014. http://www.who.int/drugresistance/documents/surveillancereport/en/. (13/04/2018).

13. Dalhoff A. Resistance surveillance studies: a multifaceted problem-the fluoroquinolone example. Infection. 2012; 40: 239-262.

14. Nicoletti J, Kuster SP, Sulser T, et al. Risk factors for urinary tract infections due to ciprofloxacin-resistant Escherichia coli in a tertiary care urology department in Switzerland. Swiss Med Wkly 2010;140: w13059.

15. Pepin J, Plamondon M, Lacroix C, Alarie I. Emergence of risk factors for ciprofloxacingentamicin-resistant Escherichia coli urinary tract infections in a region of Quebec. Can J Infect Dis Med Microbiol 2009; 20 (4): e163-168.

16. Li J, Xie S, Ahmed S, et al. Antimicrobial Activity and Resistance: Influencing Factors. Front Pharmacol. 2017; 8: 364.

17. Sommer MO, Dantas G. Antibiotics and the resistant microbiome. Curr Opin Microbiol. 2011; 14 (5): 556-563.

18. Fantin B, Duval X, Massias L, et al. Ciprofloxacin dosage and emergence of resistance in human commensal bacteria. J Infect Dis. 2009; 200 (3): 390-398.

19. Morgan DJ, Okeke IN, Laxminarayan R, Perencevich EN, Weisenberg S. Nonprescription antimicrobial use worldwide: a systematic review. Lancet Infect Dis. 2011; 11: 692-701. 